\title{
Genome-based characterization of two Colombian clinical Providencia rettgeri isolates co-harboring NDM-1, VIM-2, and other $\beta$-lactamases
}

Adriana Piza-Buitrago ${ }^{1,2}$, Verónica Rincón ${ }^{1,2}$, John Donato ${ }^{1,2}$, Sandra Yamile Saavedra ${ }^{3}$, Carolina Duarte ${ }^{3}$, Jaime Morero ${ }^{3}$, Laurent Falquet ${ }^{4}$, María Teresa Reguero ${ }^{1,2}$ and Emiliano Barreto-Hernández ${ }^{1,2^{*}}$ (D)

\begin{abstract}
Background: Providencia rettgeri is a nosocomial pathogen associated with urinary tract infections and related to Healthcare-Associated Infection (HAI). In recent years isolates producing New Delhi Metallo- $\beta$-lactamase (NDM) and other $\beta$-lactamases have been reported that reduce the efficiency of clinical antimicrobial treatments. In this study, we analyzed antibiotic resistance, the presence of resistance genes and the clonal relationship of two $P$. rettgeri isolates obtained from male patients admitted to the same hospital in Bogotá - Colombia, 2015.

Results: Antibiotic susceptibility profile evaluated by the Kirby-Bauer method revealed that both isolates were resistant to third-generation carbapenems and cephalosporins.

Whole-genome sequencing (Illumina HiSeq) followed by SPAdes assembling, Prokka annotation in combination with an in-house Python program and resistance gene detection by ResFinder identified the same six $\beta$-lactamase genes in both isolates: bla $a_{\mathrm{NDM}-1}$, bla $a_{\mathrm{VIM}-2}$, bla $a_{\mathrm{CTX}-\mathrm{M}-15}, b_{a_{\mathrm{OXA}-10},} \mathrm{bla}_{\mathrm{CMY}-2}$ and bla $a_{\mathrm{TEM}-1}$. Additionally, various resistance genes associated with antibiotic target alteration (arnA, PmrE, PmrF, LpxA, LpxC, gyrB, folP, murA, rpoB, rpsL, tet34) were found and four efflux pumps (RosAB, EmrD, $m d t H$ and $c m / A$ ).

The additional resistance to gentamicin in one of the two isolates could be explained by a detected SNP in CpxA (Cys191Arg) which is involved in the stress response of the bacterial envelope.

Genome BLAST comparison using CGView, the ANI value (99.99\%) and the pangenome (using Roary) phylogenetic tree (same clade, small distance) showed high similarity between the isolates. The rMLST analysis indicated that both isolates were typed as rST-61,696, same as the RB151 isolate previously isolated in Bucaramanga, Colombia, 2013, and the FDAARGOS_330 isolate isolated in the USA, 2015.

(Continued on next page)
\end{abstract}

\footnotetext{
* Correspondence: ebarretoh@unal.edu.co

'Bioinformatics Group, Biotechnology Institute, Universidad Nacional de Colombia, Bogotá, Colombia

${ }^{2}$ Molecular Epidemiology Laboratory, Biotechnology Institute, Universidad Nacional de Colombia, Bogotá, Colombia

Full list of author information is available at the end of the article
}

(C) The Author(s). 2020 Open Access This article is licensed under a Creative Commons Attribution 4.0 International License, which permits use, sharing, adaptation, distribution and reproduction in any medium or format, as long as you give appropriate credit to the original author(s) and the source, provide a link to the Creative Commons licence, and indicate if changes were made. The images or other third party material in this article are included in the article's Creative Commons licence, unless indicated otherwise in a credit line to the material. If material is not included in the article's Creative Commons licence and your intended use is not permitted by statutory regulation or exceeds the permitted use, you will need to obtain permission directly from the copyright holder. To view a copy of this licence, visit http://creativecommons.org/licenses/by/4.0/. The Creative Commons Public Domain Dedication waiver (http://creativecommons.org/publicdomain/zero/1.0/) applies to the data made available in this article, unless otherwise stated in a credit line to the data. 
(Continued from previous page)

Conclusions: We report the coexistence of the carbapenemase genes bla $a_{\mathrm{NDM}-1}$, and bla $a_{\mathrm{VIM}-2}$, together with the $\beta$ lactamase genes bla $a_{\mathrm{CTX}-\mathrm{M}-15}, b / a_{\mathrm{OXA}-10}, b / a_{\mathrm{CMY}-2}$ and bla $a_{\mathrm{TEM}-1}$, in P. rettgeri isolates from two patients in Colombia. Whole-genome sequence analysis indicated a circulation of P. rettgeri rST-61,696 strains in America that needs to be investigated further.

Keywords: Whole-genome sequencing, bla $a_{\mathrm{CTX}-\mathrm{M}-15}$, bla $a_{\mathrm{CMY}-2}, b / a_{\mathrm{OXA}-10}$, And bla $a_{\mathrm{TEM}-1}$

\section{Background}

Providencia rettgeri is an opportunistic pathogen mainly associated with urinary tract infections [1]; it can be a causative agent of bacteremia [2], traveler's diarrhea [3], eye infections [4] and wounds [5] and in a low incidence, of meningitis [6] and pyelonephritis [7]. In recent years, $P$. rettgeri has taken on major importance due to the emergence of carrier isolates of the New Delhi metallo$\beta$-lactamase NDM-1, a carbapenemase that hydrolyzes all $\beta$-lactams for clinical use except aztreonam [8,9]. NDM-1 was first described in 2009, in a Klebsiella pneumoniae isolated in a Swedish hospital from a patient who had been previously hospitalized in India [10]. Since then, $P$. rettgeri isolates producing NDM-1 have been reported in different parts of the world, including Asia (Nepal, Israel, India, Korea, China, Pakistan) [11-16] South America (Brazil, Argentina, Colombia, Ecuador) [17-21] North America (Canada, Mexico) [22, 23] South Africa (Nigeria) [24] and South East Europe (Bulgaria) [25].

The first report of $P$. rettgeri producing NDM-1 in Colombia was published in 2015. The isolates were obtained in 2012-2013, in the departments of Santander and Cundinamarca, and in the capital city, Bogotá [20]. In 2016, the Colombian Antimicrobial Resistance Surveillance Program in Healthcare-Associated Infections (HAI) reported $P$. rettgeri as one of the most commonly sent of the order Enterobacterales for confirmation of carbapenemases [26], and a study conducted by the National Institute of Health (INS) of Colombia in 2018 (unpublished data) P. rettgeri was determined to be the second most common carrier of the $b l a_{\mathrm{NDM}-1}$ gene among Enterobacteriaceae in this country.

The presence of $b l a_{\mathrm{NDM}-1}$ in a bacterial isolate is a challenge for clinical therapeutics. However, it is a greater challenge when it is co-harboring with other resistance determinants because it results in a greater limitation of the treatment options [27-29]. Worldwide, few reports of $P$. rettgeri notifying coexistence of $b l a_{\mathrm{NDM}-1}$ with other resistance determinants have been published. In 2014 , the first coexistence of metallo- $\beta$-lactamase bla $a_{\text {NDM-1 }}$ was reported along with $\operatorname{armA}$ encoding a $16 \mathrm{~S}$ rRNA methylase in clinical isolates of $P$. rettgeri in Nepal [11]. Recently, the coexistence of bla $a_{\mathrm{NDM}-1}$, along with other resistance determinants such as

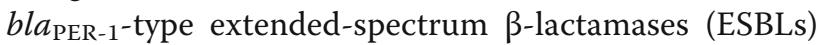
in Korea [14], and class D and A $\beta$-lactamases bla $a_{\mathrm{OXA}-48}$ and $b l a_{\mathrm{TEM}-1}$, respectively, in Turkey [30] have been described. Similarly, other coexistence in $P$. rettgeri that do not include the $b l a_{\mathrm{NDM}-1}$ gene have been described. In 2007, the co-production of PER-1, VIM-2 and ArmA in Providencia spp. isolates in Korea was reported [31]; and in Nigeria, an isolation of $P$. rettgeri was reported in 2011 carrying genes bla $a_{\mathrm{OXA}-10}, b l a_{\mathrm{VEB}-1}, b l a_{\mathrm{CMY}-4}$ and bla $a_{\mathrm{TEM}-1}$ [32].

In this study, we used whole-genome sequencing (WGS) for characterization of two $P$. rettgeri isolates that carried $b l a_{\mathrm{NDM}-1}$ and bla $a_{\mathrm{VIM}-2}$ carbapenemases, recovered in March and December 2015 at a fourth-level health care institution in Colombia.

\section{Results}

\section{Amplification and sequencing of 16S rRNA}

The 16S rRNAs obtained by PCR and sequenced for both isolates (1490 pb each of them), were aligned against the NCBI DNA nr database using blastn. The best hits of isolates GMR-RA257 and GMR-RA1153, corresponded to the seqref $16 \mathrm{~S}$ RNA of $P$. rettgeri strain RB-151 (coverage 100\%, value E 0.0, identity 100\%) and $P$. rettgeri strain FDAARGOS_330 (coverage 100\%, value E 0.0, identity 99\%), which confirmed their species identity as Providencia rettgeri.

\section{Antibiotic resistance of $P$. rettgeri isolates}

The isolates GMR-RA257 and GMR-RA1153 presented a similar susceptibility profile. Both isolates were resistant to carbapenems (imipinem, meropenem), second- (cefoxitin) and third-generation cephalosporins (ceftazidime, cefotaxime, cefepime), amikacin and trimethoprim/sulfamethoxazole and were susceptible to aztreonam and piperacillin/ tazobactam.

Some differences in the phenotypic profile of susceptibility were observed: GMR-RA257 showed an intermediate susceptibility to gentamicin, while GMR-RA1153 showed intermediate susceptibility to ertapenem. The phenotypic susceptibility profile of the $P$. rettgeri isolates showed resistance to three or more families of 
antibiotics, and therefore, both were classified as multidrug resistant (MDR) according to standardized international terminology [33].

The imipenem-EDTA/SMA double-disk synergy test confirmed the production of enzymes of the metallo- $\beta$ lactamase (MBL) type. However, the modified Hodge test $(\mathrm{MHT})$ was negative and the 3-Aminophenylboronic acid (APB)-based disk/microdilution test did not detect the production of serine-type $\beta$-lactamases.

\section{Assembly and annotation of GMR-RA257 and GMR- RA1153 genomic sequences}

Whole genome sequencing (WGS) of GMR-RA257 and GMR-RA1153 yielded 20,13 and 5,93 millions of reads respectively. These results were obtained using Illumina HiSeq 2500, and quality control was provided using FastQC, obtaining a high-quality score of Q30 (results not shown). The $\mathrm{G}+\mathrm{C}$ content for these isolates was $40.5 \%$, considered common for this species $[9,34,35]$. Detailed sequencing characteristics of GMR-RA257 and GMR-RA1153 can be found in Table S1. The estimated size of GMR-RA257 and GMR-RA1153 were $4,84 \mathrm{Mb}$ for both isolates, with a greater coverage at a depth of $744 \mathrm{X}$ and $216 \mathrm{X}$, respectively. A total of 71 tRNAs, 7 rRNAs and 4452 coding sequence (CDS) were annotated in both genomes. Those values are in the range of the previously reported genomes of $P$. rettgeri $[9,36]$. The whole-genome sequences of $P$. rettgeri GMR-RA257 and GMR-RA1153 were deposited in the DDBJ/ENA/ GenBank databases under the accession numbers VRPG00000000 and VRPH00000000 respectively. Details of the assembly and annotation for Providencia rettgeri isolates GMR-RA257 and GMR-RA1153 can be found in the supplementary Table S1.

The GMR-RA1153 and GMR-RA257 antimicrobial resistomes were obtained from their GFF files produced by Prokka v1.13. The resistomes included genes three different antibiotic resistance categories: antibiotic degradation or modification; antibiotic target alteration; and efflux pumps (Table 1). There was no difference in the type and the numbers of resistance genes present in both isolates: they showed a $100 \%$ identity with genes previously reported in the GenBank. Only the CPxA gene (histidine kinase sensor of the two-component system Cpx-TCS, involved in the stress response of the bacterial envelope) of GMR-RA1153 had a $99.93 \%$ identity with genes previously reported in GenBank and its alignment with the CpxA gene of GMR-RA257 showed a change in one amino acid (Cys191Arg).

The further results showed that plasmid-mediated genes associated with resistance to $\beta$-lactam antibiotics were the most abundant in the antibiotic degradation or modification category. This includes MBL genes encoding $b l a_{\mathrm{NDM}-1}$ and $b l a_{\mathrm{VIM}-2}$, the ESBL gene $b_{\mathrm{CTX}-\mathrm{M}-15}$, the AmpC gene $b l a_{\mathrm{CMY}-2}$, and other $\beta$ lactamases genes like $b l a_{\mathrm{OXA}-10}$, and $b l a_{\mathrm{TEM}-1}$. Further commonly detected genes were associated with aminoglycoside resistance $\left(\operatorname{ant}\left(2^{\prime \prime}\right)-\mathrm{Ia}, \operatorname{aph}\left(3^{\prime}\right)-\mathrm{VI}, \operatorname{aac}\left(6^{\prime}\right)-\mathrm{Il}\right.$, and $\operatorname{aadA} 1$ ), and sulfonamide resistance (sul1 and sul2) (Table 1).

The arnA, PmrE, PmrF, LpxA, and LpxC genes, associated with resistance to peptide antibiotics (bacitracin, colistin and polymyxin B) were the most abundant in the antibiotic target alteration category. Additionally, six different efflux pumps were identified, belonging to the major facilitator superfamily (MFS) and represented by pumps of the resistance-nodulation-cell division (RND) family (Table 1).

The carbapenemase genes $b l a_{\mathrm{NDM}-1}$ and $b l a_{\mathrm{VIM}-2}$ were found in two different contigs. Within the bla $a_{\mathrm{NDM}-1}$ contig $(7794 \mathrm{pb})$ was present the IS91 family transposase gene that could increase the $b l a_{\mathrm{NDM}-1}$ expression level $[41,42]$. This contig had $100 \%$ identity and $100 \%$ coverage with bigger plasmids present in many other bacteria like in Escherichia coli (GI: MN604268.1), Acinetobacter baumannii (GI: CP027528.1) and P. rettgeri strain RB151(GI: CP017672.1). The bla $a_{\mathrm{VIM}-2}$ contig (2011 pb) had $100 \%$ identity and coverage within 68 and $79 \%$ with bigger plasmids present in other bacteria like in Pseudomona aeruginosa (GI: KR337992.1), Acinetobacter baumannii (GI: AF324464.1) and Pseudomona putida (GI: AF327064.1). Within the small bla $a_{\mathrm{VIM}-2}$ contig was present the gene class 1 integron integrase IntI1 associated with antimicrobial resistance gene cassette. The plasmid location of the $b l a_{\mathrm{VIM}-2}$ and the other plasmid resistance-associated genes (Table 1) was supported too by the high deep of coverage of their contigs in comparison with the mean coverage of the genome contigs, and the plasmid contig identification made using PlasmiSPAdes (SPAdes v3.8.0) [39] and PlasFlow 1.1 [40].

\section{Ribosomal multilocus sequence typing (rMLST)}

The rMLST was done using the PubMLST website https://pubmlst.org/rmlst/ for the genomes of the GMRRA257 and GMR-RA1153 study and 16 Providencia rettgeri genomes available in the GenBank database. Ten of the 18 P. rettgeri genomes evaluated were assigned to seven different rST types, as follows: rST-61,696 was the predominant rST corresponding to the genomes of the study GMR-RA257, GMR-RA1153 and two genomes: RB151 isolated in Bucaramanga, Colombia, in 2013 and FDAARGOS_330 isolated in Washington D.C., the United States in 2015, both of them recovered from urine samples. The rST-37,417, rST-37,410, rST-63,059, rST-63,070, rST-37,423 and rST-37,424 were assigned to an individual reference's genomes (Table 2). 
Table 1 Resistance-associated genes in Providencia rettgeri strains GMR-RA257 and GMR-RA1153

\begin{tabular}{|c|c|c|c|c|c|c|c|}
\hline \multicolumn{2}{|c|}{ Resistance category } & \multicolumn{2}{|c|}{$\begin{array}{l}\text { Resistance } \\
\text { gene }\end{array}$} & Groups/Classes & $\begin{array}{l}\text { Gene location (C) Chromosome or } \\
\text { (P) Plasmid }{ }^{\mathrm{e}}\end{array}$ & $\begin{array}{l}\text { GMR- } \\
\text { RA257 }^{\text {a }}\end{array}$ & $\begin{array}{l}\text { GMR- } \\
\text { RA1153 a }\end{array}$ \\
\hline \multirow{17}{*}{\multicolumn{2}{|c|}{$\begin{array}{l}\text { Antibiotic } \\
\text { degradation or } \\
\text { modification }\end{array}$}} & \multicolumn{2}{|c|}{$b / a_{\mathrm{NDM}-1}$} & $\beta$-lactams & $P$ & 100.00 & 100.00 \\
\hline & & \multicolumn{2}{|c|}{ bla $a_{\mathrm{VIM}-2}$} & & $P$ & 100.00 & 100.00 \\
\hline & & \multicolumn{2}{|c|}{$b l a_{C T X-M-15}$} & & $P$ & 100.00 & 100.00 \\
\hline & & \multicolumn{2}{|c|}{$b l a_{\mathrm{CMY}-2}$} & & $P$ & 100.00 & 100.00 \\
\hline & & \multicolumn{2}{|c|}{ bla $a_{\mathrm{OX}-10}$} & & $P$ & 100.00 & 100.00 \\
\hline & & \multicolumn{2}{|c|}{$b l a_{\mathrm{TEM}-1}$} & & $P$ & 100.00 & 100.00 \\
\hline & & \multicolumn{2}{|c|}{$\operatorname{ant}(2 ")-1 a$} & Aminoglycosides & $P$ & 100.00 & 100.00 \\
\hline & & \multicolumn{2}{|c|}{$\operatorname{aph}\left(3^{\prime}\right)-\mathrm{Vl}$} & & $P$ & 100.00 & 100.00 \\
\hline & & \multicolumn{2}{|c|}{$\operatorname{aac}\left(6^{\prime}\right)-\|$} & & $P$ & 100.00 & 100.00 \\
\hline & & \multicolumn{2}{|l|}{ aadA1 } & & $P$ & 100.00 & 100.00 \\
\hline & & \multicolumn{2}{|l|}{ sul1 } & Sulphonamides & $P$ & 100.00 & 100.00 \\
\hline & & \multicolumn{2}{|l|}{ sul2 } & & $P$ & 100.00 & 100.00 \\
\hline & & \multicolumn{2}{|l|}{ gnrD1 } & Fluoroquinolones & $P$ & 100.00 & 100.00 \\
\hline & & \multicolumn{2}{|l|}{$\mathrm{cm} / \mathrm{A} 1$} & Phenicol & C & 100.00 & 100.00 \\
\hline & & \multicolumn{2}{|l|}{ ARR-2 } & Rifampicin & $P$ & 100.00 & 100.00 \\
\hline & & \multicolumn{2}{|l|}{ tet (59) } & Tetracyclines & C & 100.00 & 100.00 \\
\hline & & \multicolumn{2}{|l|}{ dfrA6 } & Trimethoprim & $P$ & 100.00 & 100.00 \\
\hline \multirow{12}{*}{\multicolumn{2}{|c|}{$\begin{array}{l}\text { Antibiotic target } \\
\text { alteration }\end{array}$}} & \multicolumn{2}{|l|}{$\operatorname{arnA}$} & Peptide antibiotics & C & 100.00 & 100.00 \\
\hline & & \multicolumn{2}{|l|}{ PmrE } & & C & 100.00 & 100.00 \\
\hline & & PmrF & & & C & 100.00 & 100.00 \\
\hline & & LpXA & & & C & 100.00 & 100.00 \\
\hline & & $L p \times C$ & & & C & 100.00 & 100.00 \\
\hline & & gyr $\mathrm{B}^{\mathrm{b}}$ & & Fluoroquinolone antibiotics & C & 100.00 & 100.00 \\
\hline & & $\begin{array}{l}\text { parcb }^{b} \\
\text { part }^{b}\end{array}$ & & & $\begin{array}{l}P \\
P\end{array}$ & $\begin{array}{l}100.00 \\
100.00\end{array}$ & $\begin{array}{l}100.00 \\
100.00\end{array}$ \\
\hline & & $f_{0} / \mathrm{P}$ & & Sulphonamides & C & 100.00 & 100.00 \\
\hline & & murA & & Fosfomycin & C & 100.00 & 100.00 \\
\hline & & rpoB & & Rifamycin & C & 100.00 & 100.00 \\
\hline & & rpsL & & Aminoglycoside antibiotics & C & 100.00 & 100.00 \\
\hline & & tet34 & & tetracyclines & C & 100.00 & 100.00 \\
\hline Efflux & MdtABC- & $\mathrm{RND}^{\mathrm{c}}$ & mdtA & Aminocoumarin antibiotics & C & 100.00 & 100.00 \\
\hline & & & $m d t B$ & & C & 100.00 & 100.00 \\
\hline & & & mdtC & & C & 100.00 & 100.00 \\
\hline & & & baeR & & C & 100.00 & 100.00 \\
\hline & & & baes & & C & 100.00 & 100.00 \\
\hline & & & CpxA & & C & 99.93 & 99.93 \\
\hline & & & CpxR & & C & 100.00 & 100.00 \\
\hline & & & TolC & & C & 100.00 & 100.00 \\
\hline & EmrAB- & $\mathrm{MFS}^{\mathrm{d}}$ & emrA & Fluoroquinolones & C & 100.00 & 100.00 \\
\hline & & & emrB & & C & 100.00 & 100.00 \\
\hline & & & emrR & & C & 100.00 & 100.00 \\
\hline & & & TolC & & C & 100.00 & 100.00 \\
\hline & AcrAB- & $\mathrm{RND}^{\mathrm{b}}$ & AcrA & Tetracyclines, cephalosporins, phenicol, rifamycin, & C & 100.00 & 100.00 \\
\hline & & & AcrB & & $C$ & 100.00 & 100.00 \\
\hline
\end{tabular}


Table 1 Resistance-associated genes in Providencia rettgeri strains GMR-RA257 and GMR-RA1153 (Continued)

\begin{tabular}{|c|c|c|c|c|c|}
\hline Resistance category & $\begin{array}{l}\text { Resistance } \\
\text { gene }\end{array}$ & Groups/Classes & $\begin{array}{l}\text { Gene location (C) Chromosome or } \\
\text { (P) Plasmid }\end{array}$ & $\begin{array}{l}\text { GMR- } \\
\text { RA257 }^{\text {a }}\end{array}$ & $\begin{array}{l}\text { GMR- } \\
\text { RA1153 }\end{array}$ \\
\hline & AcrR & & $C$ & 100.00 & 100.00 \\
\hline & To/C & & C & 100.00 & 100.00 \\
\hline \multirow[t]{2}{*}{$\operatorname{Ros} A B$} & MFS $^{d} \operatorname{ros} A$ & peptides & $C$ & 100.00 & 100.00 \\
\hline & $\operatorname{ros} B$ & & C & 100.00 & 100.00 \\
\hline EmrD & MFS $^{d} \quad E m r D$ & antibiotic efflux & C & 100.00 & 100.00 \\
\hline $\mathrm{mdtH}$ & $\mathrm{MFS}^{\mathrm{d}} \mathrm{mdtH}$ & antibiotic efflux & C & 100.00 & 100.00 \\
\hline $\mathrm{cm} \mid \mathrm{A} 5$ & MFS $^{d} \quad \mathrm{~cm} / \mathrm{A} 5$ & phenicol antibiotic & $P$ & 100.00 & 100.00 \\
\hline
\end{tabular}

a \% identity with GenBank RefSeq DNA sequences

${ }^{b}$ Gene genetic variants described previously causing resistance to fluoroquinolones [37, 38]

c RND: resistance-nodulation-cell division (RND) antibiotic efflux pump

${ }^{\mathrm{d}}$ MFS: major facilitator superfamily, antibiotic efflux pump

e The gene plasmid location was confirmed by the high deep of coverage of their contigs in comparison with the mean coverage of the genome contigs, and the plasmid contig identification made using PlasmiSPAdes (SPAdes v3.8.0) [39] and PlasFlow 1.1 [40]

\section{Whole genome comparisons}

The pangenome analysis carried out by Roary identified a total of 12, 539 genes, including 1, $217(\sim 10 \%)$ for the core genome, in the 18 genomes used in this work. The 11,322 non-central genes were divided into 6980 accessory genes and 4342 unique genes.

A phylogenetic tree was built from the core and accessory genes presence/absence information produced by Roary, using the isolates and the GenBank genomes above described, along with the rST sequence type, the country and year of collection (Fig. 1). Five important clades were observed, where the different rST types were grouped as follows: rST-37,417 (clade A); rST-37,410, rST-63,059, rST-63,070 and two genomes with no rST known (clade B); rST-37,423, rST-37,424, rST-61,696 and one genome with no rST known (clade C); two genomes with no rST known (clade D); and three genomes with no rST known (clade E) (Fig. 1). The phylogenetic tree shows a possible clonal relationship between GMR-RA257 and GMR-RA1153 which were assigned to clade $\mathrm{C}$; both isolates were recovered in Bogotá and were isolated from two patients in the same fourth level hospital in two different times (March and December, respectively). This may indicate that a clone could be circulating within this hospital during that period of time.

The average nucleotide identity (ANI) was calculated using JSpecies. JSpecies provided a 99.99\% ANI between GMR-RA257 and GMR-RA1153. Likewise, the ANI value between these genomes and the Colombian reference genome RB151 provided a value ANI of $99.67 \%$, these results showed a close relationship between the Colombian genomes.

In addition to that, a circular comparison, between the genomic sequences of GMR-RA257 and GMR-RA1153 with the Colombian genome RB151, was performed using CGView Comparison Tool (Fig. 2). The results showed that the three Colombian samples were very similar; most of the compared genomic regions of GMRRA257 and GMR-RA1153 showed a high genomic similarity (78.1\%) with RB151 (Fig. 2).

As result of the Resfinder analysis of the 18 genomes of $P$. rettgeri, the genomes pret_2032 and CCBH11880 have the highest number of genomic elements associated with resistance to different categories of antibiotics (Fig. 3). GMR-RA1153 and GMR-RA257 also have several resistance genes associated with eight different categories of antibiotics (results similar to those found in the Prokka annotation), but when compared with the other genomes, they showed the highest number of $\beta$ lactamases genes associated with resistance to $\beta$-lactam antibiotics (Fig. 3). The comparison of the GMR-RA257 and GMR-RA1153 genomes with the genome of $P$. rettgeri RB151, isolated two years earlier in Colombia, revealed that the three isolates share six different genes associated with resistance: $b l a_{\mathrm{NDM}-1}, b l a_{\mathrm{TEM}-1}$, sul1, sul2, dfrA6, tet [43]. However, in GMR-RA257 and GMRRA1153 additional genes were detected that were not present in RB151: bla $a_{\mathrm{OXA}-10}, b l a_{\mathrm{CMY}-2}, b l a_{\mathrm{CTX}-\mathrm{M}-15}$, bla ${ }_{\mathrm{VIM}-2}$, qnrD1, aadA1, aph (3')-VI, aac (6')-Il, cmlA1, $A R R-2$. The detailed results of all the antibiotic resistance genes in each class of antibiotics of each reference genome and collection strains are included in additional Table S2.

We focused our analysis on identifying nonsynonymous single nucleotide polymorphisms (nsSNPs) that result in amino acid changes within the functional gene sequences in GMR-RA257 and GMR-RA1153. We established 108 non-synonymous single nucleotide variants (nsSNVs) for GMR-RA257 and GMR-RA1153 using SnpEff. From those, 107 variants were located in genes encoding hypothetical proteins. Only one variant (Cys191Arg) present in the antibiotic resistance gene CpxA could explain the increased resistance of GMR- 
Table 2 rST and $\beta$-lactamase presence in GMR-RA257, GMR-RA1153 and 16 Providencia rettgeri genomes previously reported

\begin{tabular}{|c|c|c|c|c|c|}
\hline Isolated & AC DDBJ/ENA/GenBank & Country & Year & rST & $\beta$-lactamases \\
\hline GMR-RA257 & VRPG00000000 & Colombia & 2015 & 61,696 & $\begin{array}{l}\text { bla }_{\mathrm{NDM}-1} \\
\text { bla } \\
\text { blaXA-10 } \\
\text { bla } a_{\mathrm{CMY}-2} \\
\text { bla } \\
\text { blaX-M-15 } \\
\text { bla } a_{\mathrm{TEM}-1} \\
\text { bliM-2 }\end{array}$ \\
\hline GMR-RA1153 & VRPH00000000 & Colombia & 2015 & 61,696 & $\begin{array}{l}\text { bla }_{\mathrm{NDM}-1} \\
\text { bla } \\
\text { bl }_{\mathrm{OXA}-10} \\
\text { bla }_{\mathrm{CMX}-2} \\
\text { bl }_{\mathrm{CTEM}-15} \\
\text { bla }_{\mathrm{VIM}-2}\end{array}$ \\
\hline RB151 & NZ_CP017671 & Colombia & 2013 & 61,696 & $\begin{array}{l}\text { bla } a_{\mathrm{NDM}-1} \\
\text { bla } \\
\text { bla } a_{\mathrm{TEM}-1}\end{array}$ \\
\hline FDAARGOS_330 & NZ_CP027418 & USA & 2015 & 61,696 & N/A \\
\hline Dmel1 & NZ_CM001774 & USA & 2012 & 37,417 & N/A \\
\hline DSM1131 & ACCI00000000 & USA & 2009 & 37,410 & N/A \\
\hline AR_0082 & NZ_CP029736 & USA & 2015 & NA & $b / a_{\mathrm{NDM}-1}$ \\
\hline UBA5024 & DICO00000000 & USA & 2015 & NA & N/A \\
\hline PR1 & NOWC00000000 & USA & 2016 & 63,059 & $\begin{array}{l}\text { bla }_{\mathrm{PER}-7} \\
\text { bla } a_{\mathrm{IMP}-27} \\
\text { bla } a_{\mathrm{MP}-64} \\
\text { bla }{ }_{1 \mathrm{MP}-67}\end{array}$ \\
\hline CCBH1880 & JSEQ00000000 & Brazil & 2014 & 37,423 & $\begin{array}{l}\text { bla }_{\mathrm{NDM}-1} \\
\text { bla }_{\mathrm{OXA}-10}\end{array}$ \\
\hline $729-12$ & LYBX00000000 & Brazil & 2012 & NA & N/A \\
\hline PR002 & NXKD00000000 & South Africa & 2013 & 63,070 & $\begin{array}{l}\text { bla }_{\text {OX1-1 }} \\
\text { bla }_{\text {OXA-2 }} \\
\text { bla }_{\text {OXA-10 }} \\
\text { bla }_{\text {PER-7 }}\end{array}$ \\
\hline H1736 & CVLT00000000 & Israel & 2011 & 37,424 & $\begin{array}{l}\text { bla }_{\mathrm{NDM}-1} \\
\text { bla }\end{array}$ \\
\hline MR4 & LCVM00000000 & India & 2013 & NA & N/A \\
\hline TUM9994 & BGMI00000000 & Japon & 2010 & NA & $b l a_{C T X-M-62}$ \\
\hline Pret_2032 & QKNQ00000000 & Spain & 2015 & NA & $\begin{array}{l}b^{b} a_{\mathrm{NDM}-1} \\
\text { bla }_{\mathrm{CARB}-2} \\
\text { bla }_{\mathrm{FOX}-5} \\
\text { bla }_{\mathrm{OXA}-1} \\
\text { bla }_{\mathrm{VIM}-1}\end{array}$ \\
\hline NCTC11801 & UGTZ00000000 & United Kingdom & Strain Collection & NA & N/A \\
\hline NCTC7476 & UAUG00000000 & United Kingdom & Strain Collection & NA & N/A \\
\hline
\end{tabular}

NA Not assigned rST because the ribosomal gene alleles in the genome have not been previously reported to the BIGSdb platform N/A not available

RA1153 to the aminoglycoside antibiotic gentamicin (Table 1).

\section{Discussion}

In this study, we used WGS data to provide information on two isolates of Providencia rettgeri. We detected an uncommon accumulation of various $\beta$-lactamases genes $\left(b l a_{\mathrm{CTX}-\mathrm{M}-15}, b l a_{\mathrm{CMY}-2}, b l a_{\mathrm{OXA}-10}\right.$, and $\left.b l a_{\mathrm{TEM}-1}\right)$ genes including carbapenemase genes $b l a_{\mathrm{NDM}-1}$ and $b l a_{\mathrm{VIM}-2}$. To the best of our knowledge this combination of $\beta$ - lactamases has not been reported before in Providencia $s p p$. The isolates showed a similar resistance profile, were resistant to most of the antibiotics evaluated, except aztreonam and piperacillin/tazobactam.

Reports in America [17-19, 21-23] as well as reports in Asia [11-16] and in South Africa [24], commonly associate $P$. rettgeri with high resistance rates to $\beta$ lactamic antibiotics, a characteristic that was conserved in Colombian isolates GMR-RA257 and GMR-RA1153. This resistance trait in $P$. rettgeri is frequently associated 


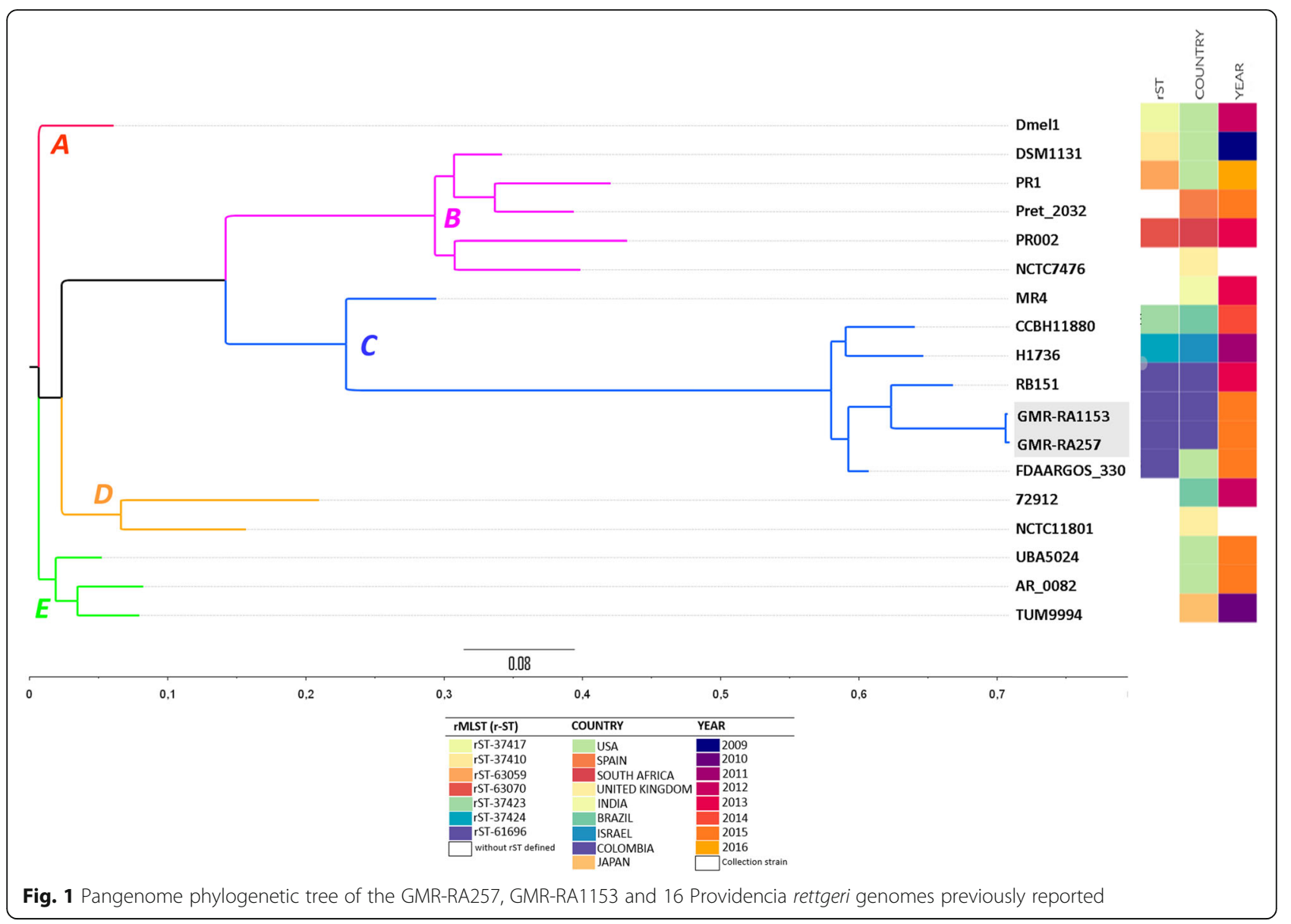

with the production of metallo- $\beta$-lactamase $\left(b l a_{\mathrm{NDM}-1}\right)$. GMR-RA257 and GMR-RA1153 were susceptible to aztreonam, similarly as previously reported in Israel, Argentina and in a former Colombian report [12, 19, 20]. It is interesting that the presence of bla $a_{\mathrm{CTX}-\mathrm{M}-15}$ gene in both isolates did not result in resistance to aztreonam, possibly due to a low expression of this gene. This agrees with different studies where many CTX-M-type ESBL-producing isolates that would previously have been reported as resistant to cephalosporins and aztreonam were now reported as susceptible to these drugs $[41,42,44]$. In isolates GMR-RA257 and GMR-RA1153 the bla $a_{\text {CTX-M-15 }}$ was located in a small contig in both isolated (2013 bp and $1924 \mathrm{bp})$ flanked upstream by a cupin-fold metalloprotein $\mathrm{WbuC}$ gene and downstream, by a fragment of transposase gene. Both $b l a_{\mathrm{CTX} \text {-M-15 }}$ contigs had $92 \%$ coverage and $100 \%$ identity with bigger plasmids present in different bacteria like E. coli (GI: MN158990.1) and K. pneunoniae (GI: CP050364.1), and therefore, they could be part of a plasmid ensembled by SPAdes in many contigs, not located into the same scaffold. However, due to the small contig size no assessment of regulatory elements of bla $a_{\mathrm{CTX}-\mathrm{M}-15}$ could be made for the two study isolates.

The rMLST analysis of GMR-RA257 and GMRRA1153 and 16 previously reported genomes, allows to identify seven different rST for ten genomes analyzed. GMR-RA257 and GMR-RA1153 belong to rST-61,696, which is the most predominant rST among the genomes used in this work. An interesting finding was that the genomes GMR-RA257 and GMR-RA1153 obtained in Bogotá in the same hospital, shared the same rST-61,696 and the same clade $C$ in the pangenome phylogenetic tree (Fig. 1), with the Colombian genome RB151 previously reported in Bucaramanga, Colombia, 2013 [8]. This indicate the presence of rST-61,696 in two different geographic locations of the country and the possible wider circulation of this $\mathrm{rST}$ in Colombia. Likewise, the FDAARGOS_330 collected in 2015, in the Children's National Hospital (USA), showed to be closely related to the Colombian genomes GMR-RA257, GMR-RA1153 and RB151 (Fig. 1) and was also typed as rST-61,696. This suggest a wider presence of $P$. rettgeri rST61696 in America.

The pangenome phylogenetic analysis suggests that GMR-RA257 and GMR-RA1153 were clonal considering 


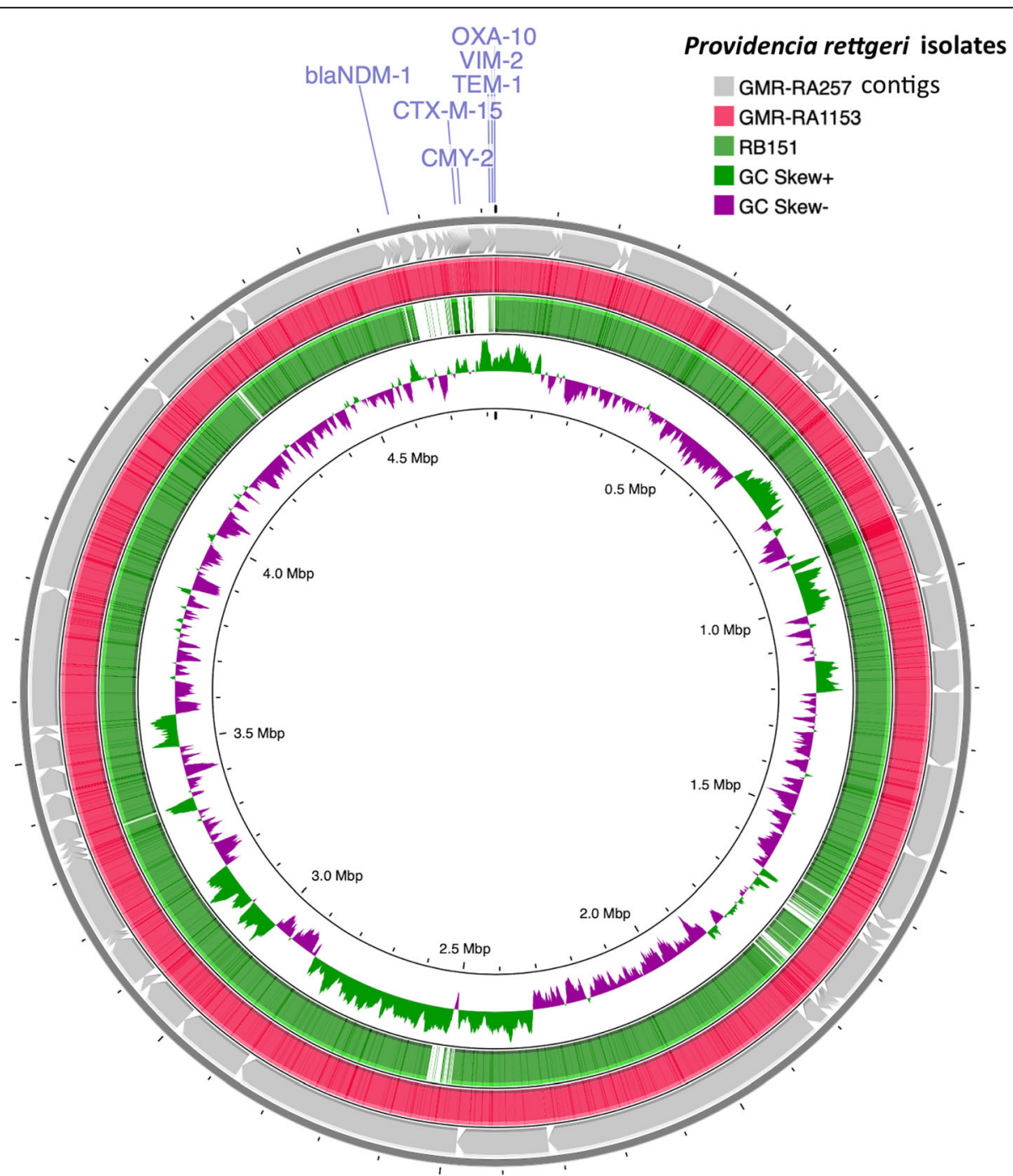

Fig. 2 BLAST comparison between GMR-RA257, GMR-RA1153 and P. rettgeri RB151 as reference genome. The innermost rings indicate GC skew (purple/green). Rings indicate BLAST identity, from inside to out: Ring 1: RB151 reference genome, Ring 2: BLAST comparison with strain GMRRA1153, Ring 3: BLAST comparison with the contigs of the strain GMR-RA1153. bla plasmid genes are showed in blue

that they were clustered very closely (distance $<0.01$ ) in the tree (Fig. 1). It was also supported because they came from the same hospital, the ANI was $99.99 \%$ and the high identity between them showed by the BLAST comparative circular visualization (Fig. 2). Furthermore, both isolates carried the same resistance genes (Table 1). There were few differences between them and the Colombian P. rettgeri RB151 previously reported [8]. These differences were principally in plasmid contigs since they were in the region $(4.6-4.9 \mathrm{Mb})$ where the plasmid contig of the reference genome $P$. rettgeri RB151 was placed (Fig. 2).

As result of the SNP analysis we detected 108 variants of a single non-synonymous nucleotide (nsSNVs). Among those 107 nsSNVs were located in genes encoding hypothetical proteins and only one variant (Cys191Arg) of the
GMR-RA1153 genome was located in the CpxA protein. $C p x \mathrm{~A}$ is a transmembrane histidine kinase sensor of the two-component system Cpx-TCS $[45,46]$, involved in the stress response of the bacterial envelope by hostile factors such as physical stress (osmolarity), chemical stress (ethanol, $\mathrm{pH}$, detergents) and misfolded proteins [45, 47]. Several studies have implicated the Cpx system in multidrug resistance (MDR), in particular to $\beta$-lactam antibiotics (imipenem, cefepime, ceftriaxone, ceftazidime, cefotaxime), chloramphenicol [45] and aminoglycosides [48]. The mutation (Cys191Arg) in $c p x \mathrm{~A}$ is located in the protein region 185-222, where have been reported mutations affecting its activity [49], which could explain the resistance profile differences: resistance and intermediate resistance to gentamicin and intermediate and resistance to ertapenem for GMR-RA1153 and GMR-RA257 respectively. 


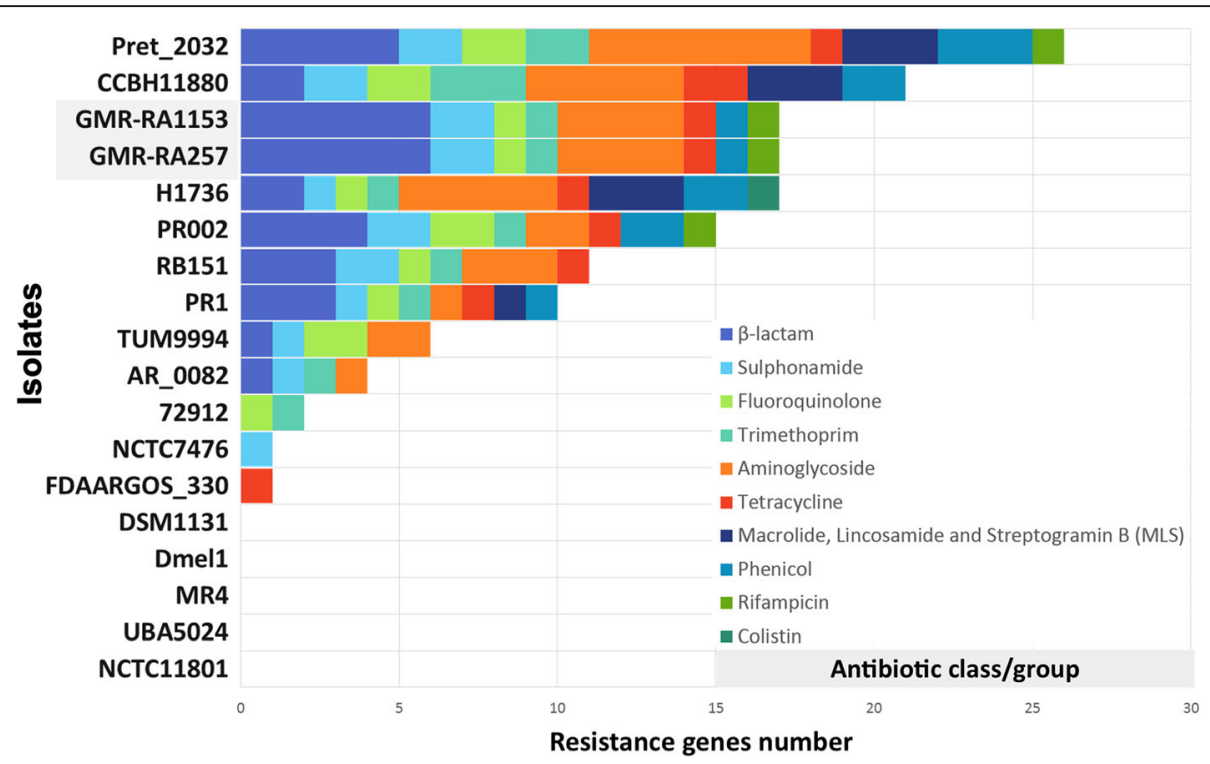

Fig. 3 Resistance genes content comparison between GMR-RA257, GMR-RA1153 and 16 Providencia rettgeri genomes previously reported

The Kirby-Bauer disk diffusion susceptibility test results interpreted using the 2015 CLSI (Clinical and Laboratory Standards Institute) guidelines [50] showed that this mutation had no influence on resistance to amikacin because both isolates were resistant. Probably, some of the other SNPs could contribute to this variation, but more research will be necessary for understanding how the SNPs located in unknown proteins or in non-coding regions influence the resistance.

The isolates GMR-RA257 and GMR-RA1153 showed an uncommon high number of $\beta$-lactamase genes. The ESBL and AmpC $\beta$-lactamase genes bla $a_{\mathrm{CTX}-\mathrm{M}-15}$ and bla $a_{\mathrm{CMY}-2}$ have not been reported previously in $P$. rettgeri isolates and only one study has described the presence of carbapenemase NDM-1 together with an ESBL as PER-1 [31]. Furthermore, there is not a previously report of NDM-1 together with another ESBL such as CTX-M-15.

Apart from the high number of $\beta$-lactamase genes in both study isolates further resistance genes arnA, PmrE, PmrF, LpxA, LpxC, gyrB, folP, murA, rpoB, rpsL, and tet34 genes were found that have been reported previously in Enterobacterales species but no in P. rettgeri. Additionally, four efflux pumps of the MFS family: $\operatorname{Ros} A B$ (rosA, $\operatorname{ros} B), E m r D, m d t H$ and $c m l A$, were not previously reported in $P$. rettgeri.

GMR-RA257 and GMR-RA1153 were resistant to the carbapenems imipenem and meropenem; this was highly probable caused by the production of MBL types NDM1 and VIM-2 $[51,52]$ and the expression of bla $a_{\text {OXA-10 }}$ encoding an enzyme that is currently associated with weak hydrolysis of carbapenem, and whose inclusion is proposed within the group of carbapenem-hydrolyzing class D $\beta$-lactamases (CHDLs) $[53,54]$. In a study in Nigeria in 2011 a carbapenem susceptible $P$. rettgeri isolate was reported that carried $b l a_{\mathrm{OXA}-10}, b l a_{\mathrm{VEB}-1}$ and $b l a_{\mathrm{CMY}-4}$ genes with no presence of the $b l a_{\mathrm{NDM}-1}$ gene [32]. These results show that the presence of MBL as $b l a_{\mathrm{NDM}-1}$ and $b l a_{\mathrm{VIM}-2}$ contribute to carbapenem resistance, which is a serious problem for clinicians, as these are considered last-resort antibiotics. Unfortunately, antimicrobials such as colistin and tigecycline -which are now used as antibiotics to treat multidrug-resistant microorganisms producing carbapenemase [55]- are not a treatment option for $P$. rettgeri isolates, due to the natural resistance of the latter to the said antibiotics $[56,57]$. However, a possible treatment option is a combination: Avibactam, non- $\beta$-lactam inhibitor with activity against serine $\beta$-lactamase classes $A, C$ and D [58]; and aztreonam, resistant to the hydrolysis of MBL. In vitro studies demonstrated good results in the values of minimum inhibitory concentration (MIC) for Enterobacterales isolates that produced MBL and serine $\beta$-lactamases such as ESBL and / or AmpC [43, 59]. Aztreonam-avibactam is not yet approved by the U.S. Food and Drug Administration (FDA), but clinicians can administer this combination $[43,59,60]$.

\section{Conclusions}

Whole genome analysis of the two clinical P. rettgeri isolates GMB-RA257 and GMB-RA1153 revealed that both isolates harbored an uncommon combination of various $\beta$-lactamase genes: bla $a_{\mathrm{NDM}-1}, \quad b l a_{\mathrm{VIM}-2}, \quad b l a_{\mathrm{CTX}-\mathrm{M}-15}$, $b l a_{\mathrm{CMY}-2}, b l a_{\mathrm{OXA}-10}$, and $b l a_{\mathrm{TEM}-1}$, that have not been reported previously in this microorganism. 
The comparative genomic analyses revealed a close relationship of the isolates; the assigned rST-61,696 was found previously in Colombia and the USA.

The differences of both isolates in gentamicin susceptibility could be explained by a Cys191Arg substitution in the CpxA protein.

Our finding shows the need of detailed and continuous molecular epidemiological surveillance of $P$. rettgeri to assess the regional and worldwide spread of clones and to detect early the acquisition of resistance genes that limit dramatically limit the treatment options for infections with this pathogen.

\section{Methods}

\section{Bacterial isolates}

The Microbiology Group of the National Institute of Health (INS) of Colombia received the isolates GMRRA257 and GMR-RA1153 that exhibited a decreased susceptibility to carbapenems, as part of the HealthcareAssociated Infection (HAI) Surveillance Program. The isolates were recovered from urine samples obtained from two patients admitted to a 4th level hospital in Bogotá - Colombia, in different months of 2015. GMRRA1153 was isolated from a patient who was in an intensive care unit (ICU), and GMR-RA257 without data from the collection site. The two isolates were identified as Providencia rettgeri, using the automatic VITEK $^{\circ} 2$ system (bioMérieux).

\section{Molecular identification}

An amplification of the 16S rRNA gene $(\sim 1.5 \mathrm{~kb})$ was made to confirm the genus and species of each isolate. For this, the universal primers Forward 27F 5 'AGAGTT TGATCMTGGCTCAG 3' and Reverse 1492R 5 'TACG GYTACCTTGTTACGACTT 3' were used. Purified PCR products were sequenced, using the BigDye methodology and following the manufacturer's protocol (Applied Biosystems, Foster City, United States) at the sequencing service of the Institute of Genetics at Universidad Nacional de Colombia. Chromatograms were analyzed using Chromas program (Technelysium Pty Ltd.). The 16S rRNA sequencing data were aligned and compared with those available in the NCBI (National Center for Biotechnology Information) GenBank database using the BLASTn algorithm.

\section{Susceptibility testing}

The antibiotic susceptibility profile was determined using the Kirby-Bauer disk diffusion susceptibility test. The following disks were tested: cefepime (FEP), cefoxitin (FOX), cefotaxime (CTX), ceftazidime (CAZ), ertapenem (ERT), imipenem (IMI), meropenem (MEM), aztreonam (ATM), ciprofloxacin (CIP), amikacin (AK), piperacillin/tazobactam (TZP) and trimethoprim/sulfamethoxazole (SXT). The susceptibility results were interpreted using the 2015 CLSI (Clinical and Laboratory Standards Institute) guidelines [50].

\section{Confirmation of carbapenemase production}

Phenotypic detection of carbapenemases was performed using modified Hodge test (MHT) [33], and two doubledisc synergy tests with specific inhibitors: ethylenediaminetetraacetic acid / mercaptoacetic acid (EDTA / SMA) and phenyl boronic acid (APB). For the MHT, the reference strain Escherichia coli ATCC 25922 was used as the indicator organism, strain $K$. pneumoniae BAA 1705 as positive control and strain $K$. pneumoniae BAA 1706 as negative control. For the EDTA / SMA test the positive control used was $K$. pneumoniae BAA 2146 and for the APB test was the strain $K$. pneumoniae BAA 1705. The synergy of the antibiotic imipenem towards EDTA/SMA was interpreted as a positive result for the presence of class B carbapenemase. Similarly, the halo distortion of the antibiotic imipenem towards APB was interpreted as a positive result for the presence of class A carbapenemase.

\section{Whole genome sequencing}

The isolates' genomic DNA was obtained by using two commercial kits, according to the manufacturer's recommendations: QIAamp DNA mini kit (Qiagen) for GMRRA1153, and PureLink ${ }^{\circ}$ Genomic DNA Kit (Thermo Fisher Scientific / Invitrogen) for GMR-RA257. DNA quantification was estimated by the PicoGreen method, using Vector 3 fluorometry. The final Paired-End sequencing was done with the Illumina HiSeq 2500 platform (the TruSeq Nano DNA kit (Illumina) was used for library construction). The quality of the raw paired-end reads was assessed by FastQC $\mathrm{v} 0.11 .7$ [61], and the trimming of poor-quality bases $(<\mathrm{Q} 30$ and $<1000 \mathrm{bp}$ ) was done using the Sickle v1.33 tool [62]. Subsequently, the reads were de novo assembled using SPAdes v3.8.0 [39]. The annotation process was done using Prokka v1.13 [63], which was enriched with the following resistance databases: CARD [64], Resfam [65], GIPSy [66] and VFDB [67] and we complete the analysis with the Resfinder database (https://cge.cbs. dtu.dk/services/ResFinder/).

\section{Providencia rettgeri genome sequence data}

The genomes GMR-RA257 and GMR-RA1153 were compared with 16 genomes of Providencia rettgeri available in GenBank: 14 reference genomes (RB151, H1736, CCBH11880, FDAARGOS_330, MR4, 729-12, UBA5024, AR_0082, TUM9994, Dmel1, DSM1131, PR1, Pret_2032, PR002); and 2 collection strains: (NCTC11801, NCTC74801). An important factor to take into account is that these genomes were used 
without discrimination of chromosome and plasmid sequences.

\section{Ribosomal multilocus sequence typing (rMLST)}

The Ribosomal Multi-Locus Sequence Typing Scheme described by Jolley et al. [68] and hosted on the PubMLST website https://pubmlst.org/rmlst/ was used for the typing of the isolates of this work. Ribosomal Multilocus Sequence Typing (rMLST) is an approach that indexes the variation of the 53 genes encoding the bacterial ribosome protein subunits (rps, rpl, rpm genes) as a means of integrating microbial typing. The allelic variation rMLST is cataloged using the BIGSdb platform [44]: scalable, open source database that allows to store sequences and allelic definitions for defined loci [69] For the study, the rMLST scheme first identified the nucleotide sequences of the genes (rps, rpl, rpm) of the annotated genomes; then, defined the unique alleles for each of these genes based on their nucleotide sequence; and finally, assigned each genome a customized ribosomal sequence type ( $\mathrm{rST}$ ) number defined by the allelic profile of the numerical combination of the 53 genes.

\section{Whole genome comparisons}

Using the Providencia Rettgeri genome sequence data described above the pangenome was inferred with Roary version 3.7.0 [70]. Roary produced a gene presence/absence matrix, a multi-FASTA alignment of core genes using PRANK version 0.140603 [71] and a phylogenetic tree based on the presence and absence of accessory genes among taxa using FastTree version 2.1.9 [72].

Visualization of circular genome BLASTN-based comparisons between Colombian reference genome RB151 and the genomes GMR-RA257 and GMR-RA1153, in order to show a broad genome visualization of the identity of the coding, was done using CGView Comparison Tool [73].

The average nucleotide identity (ANI) approach was used [74] to determine the genetic relationship between GMR-RA257 and GMR-RA1153. ANI was calculated within the JSpecies software [75]. GMR-RA257 and GMR-RA1153 were aligned with Mauve version 2.4.0 [76]. From this alignment, a file with the SNPs was obtained using Mauve 2.4.0 and converted to VCF format using an in-house Perl script. Finally, the SNPs were annotated with the snpEff program (http://snpeff. sourceforge.net).

The detection of these resistance genes for Providencia Rettgeri genome sequence data was performed using the program Resfinder (https://cge.cbs.dtu.dk/ services/ResFinder/), using the fasta files of the 18 genomes of P. rettgeri (GMR-RA257 and GMR-RA1153, 14 reference genomes and 2 collection strains).

\section{Supplementary Information}

The online version contains supplementary material available at https://doi. org/10.1186/s12866-020-02030-z.

Additional file 1 Table S1. Assembly and annotation Providencia rettgeri isolates GMR-RA257 and GMR-RA1153.

Additional file 2 Table S2. Antibiotic resistance present in GMR-RA257, GMR-RA1153, and 16 Providencia rettgeri genomes previously reported.

\section{Abbreviations}

ANI: Average Nucleotide Identity; APB: Phenyl Boronic Acid; EDTA / SMA: Ethylenediaminetetraacetic acid / Mercaptoacetic acid; ICU: Intensive Care Unit; INS: National Institute of Health; MDR: Multi Drug-Resistant; MHT: Modified Hodge test; rMLST: Ribosomal Multilocus Sequence Typing; rST: Ribosomal Sequence Type; SNP: Single-Nucleotide Polymorphism; WGS: Whole-Genome Sequencing

\section{Acknowledgments}

We would like to thank the Microbiology group of the National Institute of Health of Colombia, the Molecular Epidemiology Laboratory and the Bioinformatics Group of the Universidad Nacional de Colombia and the Research Division of the Universidad Nacional de Colombia at BogotáColombia

\section{Authors' contributions}

AP-B and VR were responsible for designing experiment, whole genome sequencing, genotyping and Pangenome Analysis and writing manuscript. JD was responsible for bioinformatics analysis. SYS, CD and JM were responsible for recovery and identification of isolates, susceptibility testing and phenotypic detection of carbapenemases. LF was responsible for bioinformatics analysis. MTR was responsible for designing experiment and resistance gene analysis. EB-H was responsible for designing experiment, bioinformatics analysis and writing the manuscript. All authors read and approved the final manuscript.

\section{Funding}

The Universidad Nacional de Colombia at Bogotá (Project 35030) financially supported this work and the design of the study, analysis, and interpretation of data, and manuscript writing. The Instituto Nacional de Salud de

Colombia supported the collection, analysis, and interpretation of data. The Departamento Administrativo de Ciencia y Tecnología, COLCIENCIAS under the Convocatoria 656, 2014, Es Tiempo de Volver (FP44842-155-2015) financially supported the VR postdoctoral fellow.

\section{Availability of data and materials}

Sequence data of this project have been deposited in the DDBJ/EMBL/ GenBank of the National Center for Biotechnology Information (NCBI) under the accession number VRPG00000000 and VRPH00000000.

\section{Ethics approval and consent to participate}

The isolates GMR-RA257 and GMR-RA1153 analyzed in this manuscript were recovered as part of the national surveillance program by the antimicrobial resistance Healthcare-associated infections (HAls) laboratory of the National Institute of Health of Colombia. Due that the isolates are part of a national public health surveillance program, they do not require informed consent (decrees 2323 and 3518 of 2006 of the Social Protection Ministry of Colombia).

Consent for publication

Not Applicable.

\section{Competing interests}

The authors declare that they have no competing interests.

\section{Author details}

${ }^{1}$ Bioinformatics Group, Biotechnology Institute, Universidad Nacional de Colombia, Bogotá, Colombia. ${ }^{2}$ Molecular Epidemiology Laboratory, Biotechnology Institute, Universidad Nacional de Colombia, Bogotá, Colombia. ${ }^{3}$ Grupo de Microbiología, Instituto Nacional de Salud, Bogotá, Colombia. ${ }^{4}$ Biochemistry/Bioinformatics Unit, Université de Fribourg and Swiss Institute of Bioinformatics, Fribourg, Switzerland. 
Received: 28 November 2019 Accepted: 2 November 2020

Published online: 12 November 2020

\section{References}

1. O'Hara CM, Brenner FW, Miller JM. Classification, identification, and clinical significance of Proteus, Providencia, and Morganella. Clin Microbiol Rev. 2000; 13(4):534-46.

2. Wie S-H. Clinical significance of Providencia bacteremia or bacteriuria. Korean J Intern Med. 2015;30(2):167-9.

3. Yoh M, Matsuyama J, Ohnishi M, Takagi K, Miyagi H, Mori K, et al. Importance of Providencia species as a major cause of travellers' diarrhoea. J Med Microbiol. 2005;54(11):1077-82.

4. Koreishi AF, Schechter BA, Karp CL. Ocular infections caused by Providencia rettgeri. Ophthalmology. 2006;113(8):1463-6.

5. Washington MA, Barnhill J, Griffin JM. A case of wound infection with Providencia rettgeri and coincident gout in a patient from Guam. Hawaii J Med Public Health. 2015;74(11):375-7.

6. Maiti TK, Pandey P, Singh VK. Providencia rettgeri: an unusual cause of central nervous system infections. Am J Med Sci. 2013;346(2):158-9.

7. Lee $\mathrm{G}$, Hong $J \mathrm{H}$. Xanthogranulomatous pyelonephritis with nephrocutaneous fistula due to Providencia rettgeri infection. J Med Microbiol. 2011;60(7):1050-2.

8. Marquez-Ortiz RA, Haggerty L, Sim EM, Duarte C, Castro-Cardozo BE, Beltran $M$, et al. First Complete Providencia rettgeri Genome Sequence, the NDM-1Producing Clinical Strain RB151. Genome Announc. 2017;5(3):e01472-16. https://doi.org/10.1128/genomeA.01472-16.

9. Olaitan AO, Diene SM, Assous MV, Rolain J-M. Genomic plasticity of multidrug-resistant NDM-1 positive clinical isolate of Providencia rettgeri. Genome Biol Evol. 2015:8(3):723-8.

10. Yong D, Toleman MA, Giske CG, Cho HS, Sundman $K$, Lee $K$, et al. Characterization of a new Metallo- $\beta$-lactamase gene, bla $a_{\mathrm{NDM}-1}$, and a nove erythromycin esterase gene carried on a unique genetic structure in Klebsiella pneumoniae sequence type 14 from India. Antimicrob Agents Chemother. 2009;53(12):5046-54.

11. Tada T, Miyoshi-Akiyama T, Dahal RK, Sah MK, Ohara H, Shimada K, et al. NDM-1 Metallo- $\beta$-lactamase and ArmA 165 rRNA methylase producing Providencia rettgeri clinical isolates in Nepal. BMC Infect Dis. 2014;14:56.

12. Gefen-Halevi S, Hindiyeh MY, Ben-David D, Smollan G, Gal-Mor O, Azar R, et al. Isolation of genetically unrelated b/a $a_{\mathrm{NDM}-1}$ positive Providencia rettgeri strains in Israel. J Clin Microbiol. 2013;51(5):1642-3.

13. Lascols C, Hackel M, Marshall SH, Hujer AM, Bouchillon S, Badal R, et al. Increasing prevalence and dissemination of NDM-1 metallo- $\beta$-lactamase in India: data from the SMART study (2009). J Antimicrob Chemother. 2011; 66(9):1992-7.

14. Shin S, Jeong SH, Lee H, Hong JS, Park M-J, Song W. Emergence of multidrug-resistant Providencia rettgeri isolates co-producing NDM-1 carbapenemase and PER-1 extended-spectrum $\beta$-lactamase causing a first outbreak in Korea. Ann Clin Microbiol Antimicrob. 2018;17(1):20.

15. Zhou G, Guo S, Luo Y, Ye L, Song Y, Sun G, et al. NDM-1-producing strains, family Enterobacteriaceae, in hospital, Beijing, China. Emerg Infect Dis. 2014; 20(2):340-2.

16. Perry JD, Naqvi SH, Mirza IA, Alizai SA, Hussain A, Ghirardi S, et al. Prevalence of faecal carriage of Enterobacteriaceae with NDM-1 carbapenemase at military hospitals in Pakistan, and evaluation of two chromogenic media. J Antimicrob Chemother. 2011;66(10):2288-94.

17. Carvalho-Assef APD, Pereira PS, Albano RM, Berião GC, Chagas TPG, Timm LN, et al. Isolation of NDM-producing Providencia rettgeri in Brazil. J Antimicrob Chemother. 2013;68(12):2956-7.

18. do Carmo Junior NV, Filho HF, Costa DA GE, AJW C, de O GD, JJD F. First report of a NDM-producing Providencia rettgeri strain in the state of São Paulo. Braz J Infect Dis Off Publ Braz Soc Infect Dis. 2015;19(6):675-6.

19. Pasteran F, Meo A, Gomez S, Derdoy L, Albronoz E, Faccone D, et al. Emergence of genetically related NDM-1-producing Providencia rettgeri strains in Argentina. J Glob Antimicrob Resist. 2014:2(4):344-5.

20. Saavedra-Rojas S-Y, Duarte-Valderrama C, González-de-Arias M-N, OvalleGuerro MV. Emergencia de Providencia rettgeri NDM-1 en dos departamentos de Colombia, 2012-2013. Enfermedades Infecc Microbiol Clínica. 2017:35(6):354-8.

21. Zurita J, Parra H, Gestal MC, McDermott J, Barba P. First case of NDM-1producing Providencia rettgeri in Ecuador. J Glob Antimicrob Resist. 2015; 3(4):302-3.
22. Kus JV, Tadros M, Simor A, Low DE, McGeer AJ, Willey BM, et al. New Delhi metallo- $\beta$-lactamase-1: local acquisition in Ontario, Canada, and challenges in detection. CMAJ Can Med Assoc J. 2011;183(11):1257-61.

23. Barrios H, Garza-Ramos U, Reyna-Flores F, Sanchez-Perez A, Rojas-Moreno T, Garza-Gonzalez E, et al. Isolation of carbapenem-resistant NDM-1-positive Providencia rettgeri in Mexico. J Antimicrob Chemother. 2013;68(8):1934-6.

24. Tshisevhe VS, Lekalakala MR, Tshuma N, Janse van Rensburg S, Mbelle N. Outbreak of carbapenem-resistant Providencia rettgeri in a tertiary hospital. South Afr Med J Suid-Afr Tydskr Vir Geneeskd. 2016;107(1):31-3.

25. Pfeifer Y, Trifonova A, Pietsch M, Brunner M, Todorova I, Gergova I, et al. Clonal transmission of gram-negative Bacteria with Carbapenemases NDM1, VIM-1, and OXA-23/72 in a Bulgarian hospital. Microb Drug Resist Larchmt N. 2017:23(3):301-7.

26. Ovalle MV, Rojas SYS, Valderrama CD, Durán MA. Title of subordinate document. In: Resultados del Programa de Vigilancia por Laboratorio de Resistencia antimicrobiana en Infecciones Asociadas a la Atención en Salud (IAAS) 2016; 2016. https://www.ins.gov.co/buscador-eventos/Informacin\%2 0de\%20laboratorio/Informe\%20Vigilancia\%20por\%20Laboratorio\%2 OResistencia\%20Antimicrobiana\%20y\%20Whonet\%20|AAS\%202016.pdf. Accessed 10 October 2019

27. Oteo J, Miró E, Pérez-Vázquez M, Navarro F. Evolution of carbapenemaseproducing Enterobacteriaceae at the global and national level: what should be expected in the future? Enferm Infecc Microbiol Clin. 2014;32(Suppl 4): $17-23$.

28. Blakiston $M$, Heffernan $H$, Roberts $S$, Freeman J. The clear and present danger of carbapenemase-producing Enterobacteriaceae (CPE) in New Zealand: time for a national response plan. N Z Med J. 2017;130(1454):72-9.

29. Dhillon RH-P, Clark J. ESBLs: a clear and present danger? Crit Care Res Pract. 2012;2012:625170

30. Otlu B, Yakupoğulları Y, Gürsoy NC, Duman Y, Bayındır Y, Tekerekoğlu MS, et al. Co-production of OXA-48 and NDM-1 Carbapenemases in Providencia rettgeri: the first report. Mikrobiyol Bul. 2018;52(3):300-7.

31. Lee H-W, Kang H-Y, Shin K-S, Kim J. Multidrug-resistant Providencia isolates

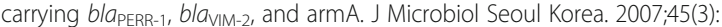
272-4.

32. Aibinu IE, Pfeifer $Y$, Ogunsola F, Odugbemi T, Koenig W, Ghebremedhin B. Emergence of $\beta$-lactamases OXA-10, VEB-1 and CMY in Providencia spp. from Nigeria. J Antimicrob Chemother. 2011;66(8):1931-2.

33. Magiorakos A-P, Srinivasan A, Carey RB, Carmeli Y, Falagas ME, Giske CG, et al. Multidrug-resistant, extensively drug-resistant and pandrug-resistant bacteria: an international expert proposal for interim standard definitions for acquired resistance. Clin Microbiol Infect Off Publ Eur Soc Clin Microbiol Infect Dis. 2012;18(3):268-81.

34. Galac MR, Lazzaro BP. Comparative genomics of bacteria in the genus Providencia isolated from wild Drosophila melanogaster. BMC Genomics. 2012;13:612.

35. Pereira PS, Albano RM, Asensi MD, Carvalho-Assef APD. Draft genome sequences of three NDM-1-producing Enterobacteriaceae species isolated from Brazil. Mem Inst Oswaldo Cruz. 2015;110(4):580-2.

36. Wang G-H, Brucker RM. Genome sequence of Providencia rettgeri NVIT03, isolated from Nasonia vitripennis. Microbiol Resour Announc. 2019;8(3): e01157-18.

37. Nawaz M, Sung K, Kweon O, Khan S, Nawaz S, Steele R. Characterisation of novel mutations involved in quinolone resistance in Escherichia coli isolated from imported shrimp. Int J Antimicrob Agents. 2015;45(5):471-6.

38. O'Regan E, Quinn T, Pagès J-M, McCusker M, Piddock L, Fanning S. Multiple regulatory pathways associated with high-level ciprofloxacin and multidrug resistance in salmonella enterica Serovar Enteritidis: involvement of ramA and other global regulators. Antimicrob Agents Chemother. 2009;53(3): 1080-7.

39. Bankevich A, Nurk S, Antipov D, Gurevich AA, Dvorkin M, Kulikov AS, et al. SPAdes: a new genome assembly algorithm and its applications to singlecell sequencing. J Comput Biol J Comput Mol Cell Biol. 2012;19(5):455-77.

40. Krawczyk PS, Lipinski L, Dziembowski A. PlasFlow: predicting plasmid sequences in metagenomic data using genome signatures. Nucleic Acids Res. 2018;46(6):e35.

41. Pecora N, Zhao X, Nudel K, Hoffmann M, Li N, Onderdonk A, Yokoe D, Brown $E$, Allard $M$, Bry L. Diverse vectors and mechanisms spread New Delhi Metallo- $\beta$-lactamases among Carbapenem-resistant Enterobacteriaceae in the greater Boston area. Antimicrob Agents Chemother. 2019;63(2):e02040-18. 
42. Partridge S, Kwong S, Firth N, Jensenc S. Mobile genetic elements associated with antimicrobial resistance. Clin Microbiol Rev. 2018;31:e00088-17.

43. Wu W, Feng Y, Tang G, Qiao F, McNally A, Zong Z. NDM Metallo- $\beta$ lactamases and their bacterial producers in health care settings. Clin Microbiol Rev. 2019;32(2):e00115-8.

44. Jolley KA, Maiden MCJ. BIGSdb: scalable analysis of bacterial genome variation at the population level. BMC Bioinformatics. 2010;11:595.

45. Srinivasan VB, Vaidyanathan V, Mondal A, Rajamohan G. Role of the Two Component Signal Transduction System CpxAR in Conferring Cefepime and Chloramphenicol Resistance in Klebsiella pneumoniae NTUH-K2044. PLOS ONE. 2012;7(4):e33777

46. DiGiuseppe PA, Silhavy TJ. Signal detection and target gene induction by the CpxRA two-component system. J Bacteriol. 2003;185(8):2432-40.

47. MacRitchie DM, Buelow DR, Price NL, Raivio TL. Two-component signaling and gram negative envelope stress response systems. Adv Exp Med Biol. 2008;631:80-110.

48. Hirakawa H, Nishino K, Hirata T, Yamaguchi A. Comprehensive studies of drug resistance mediated by overexpression of response regulators of twocomponent signal transduction Systems in Escherichia coli. J Bacteriol. 2003; 185(6):1851-6.

49. Mechaly AE, Sassoon N, Betton JM, Alzari PM. Segmental helical motions and dynamical asymmetry modulate histidine kinase autophosphorylation. PLoS Biol. 2014;12(1):e1001776.

50. Clinical and Laboratory Standards Institute. 2015. Performance standards for antimicrobial susceptibility testing, M100-S25. Wayne, PA.

51. Poirel L, Naas T, Nordmann P. Diversity, epidemiology, and genetics of class D B-lactamases. Antimicrob Agents Chemother. 2010;54(1):24-38.

52. Antunes NT, Lamoureaux TL, Toth M, Stewart NK, Frase H, Vakulenko SB. Class D $\beta$-lactamases: are they all carbapenemases? Antimicrob Agents Chemother. 2014;58(4):2119-25.

53. Ye Y, Xu L, Han Y, Chen Z, Liu C, Ming L. Mechanism for carbapenem resistance of clinical Enterobacteriaceae isolates. Exp Ther Med. 2018;15(1): 1143-9

54. Khan AU, Maryam L, Zarrilli R. Structure, genetics and worldwide spread of New Delhi Metallo- $\beta$-lactamase (NDM): a threat to public health. BMC Microbiol. 2017:17(1):101.

55. Stock I. Infectious diseases caused by carbapenemase-producing Enterobacteriaceae--a particular challenge for antibacterial therapy. Med Monatsschr Pharm. 2014;37(5):162-72 quiz 173-4.

56. Rose WE, Rybak MJ. Tigecycline: first of a new class of antimicrobial agents. Pharmacotherapy. 2006;26(8):1099-110.

57. Choi HK, Kim YK, Kim HY, Park JE, Uh Y. Clinical and microbiological features of Providencia bacteremia: experience at a tertiary care hospital. Korean J Intern Med. 2015;30(2):219-25.

58. Bush K, Bradford PA. Interplay between $\beta$-lactamases and new $\beta$-lactamase inhibitors. Nat Rev Microbiol. 2019;17(5):295.

59. Karlowsky JA, Kazmierczak KM, de Jonge BLM, Hackel MA, Sahm DF, Bradford PA. In Vitro Activity of Aztreonam-Avibactam against Enterobacteriaceae and Pseudomonas aeruginosa Isolated by Clinical Laboratories in 40 Countries from 2012 to 2015. Antimicrob Agents Chemother. 2017;61(9):e00472-17. https://doi.org/10.1128/AAC.00472-17.

60. Emeraud C, Escaut L, Boucly A, Fortineau N, Bonnin RA, Naas T, et al. Aztreonam plus Clavulanate, Tazobactam, or Avibactam for treatment of infections caused by Metallo- $\beta$-lactamase-producing gram-negative Bacteria. Antimicrob Agents Chemother. 2019:63(5):e00010-9.

61. Andrews S. Title of subordinate document. In: FastQC A Quality Control tool for High Throughput Sequence Data; 2013. http://www.bioinformatics. babraham.ac.uk/projects/fastqc/. Accessed 10 October 2019

62. Joshi N, Fass J. Title of subordinate document. In: Sickle: A sliding-window, adaptive, quality-based trimming tool for FastQ files; 2011. http://github. com/najoshi/sickle. Accessed 10 October 2019.

63. Seemann T. Prokka: rapid prokaryotic genome annotation. Bioinforma Oxf Engl. 2014;30(14):2068-9

64. McArthur AG, Waglechner N, Nizam F, Yan A, Azad MA, Baylay AJ, et al. The comprehensive antibiotic resistance database. Antimicrob Agents Chemother. 2013:57(7):3348-57.

65. Gibson MK, Forsberg KJ, Dantas G. Improved annotation of antibiotic resistance determinants reveals microbial resistomes cluster by ecology. ISME J. 2015;9(1):207-16.

66. Soares SC, Geyik H, Ramos RTJ, de Sá PHCG, Barbosa EGV, Baumbach J, et al. GIPSy: genomic island prediction software. J Biotechnol. 2016;232:2-11.
67. Chen L, Zheng D, Liu B, Yang J, Jin Q. VFDB 2016: hierarchical and refined dataset for big data analysis-10 years on. Nucleic Acids Res. 2016; 44(Database issue):D694-7.

68. Jolley KA, Bliss CM, Bennett JS, Bratcher HB, Brehony C, Colles FM, et al. Ribosomal multilocus sequence typing: universal characterization of bacteria from domain to strain. Microbiol Read Engl. 2012;158(Pt 4):1005-15.

69. Jolley KA, Bray JE, Maiden MCJ. Open-access bacterial population genomics: BIGSdb software, the PubMLST.org website and their applications. Wellcome Open Res. 2018. https://doi.org/10.12688/wellcomeopenres.14826.1.

70. Page AJ, Cummins CA, Hunt M, Wong VK, Reuter S, Holden MTG, et al. Roary: rapid large-scale prokaryote pan genome analysis. Bioinforma Oxf Engl. 2015;31(22):3691-3

71. Löytynoja A. Phylogeny-aware alignment with PRANK. Methods Mol Biol Clifton NJ. 2014;1079:155-70.

72. Price MN, Dehal PS, Arkin AP. FastTree: computing large minimum evolution trees with profiles instead of a distance matrix. Mol Biol Evol. 2009;26(7): 1641-50.

73. Grant JR, Arantes AS, Stothard P. Comparing thousands of circular genomes using the CGView comparison tool. BMC Genomics. 2012;13:202.

74. Figueras MJ, Beaz-Hidalgo R, Hossain MJ, Liles MR. Taxonomic affiliation of new genomes should be verified using average nucleotide identity and multilocus phylogenetic analysis. Genome Announc. 2014;2(6):e00927-14.

75. Richter M, Rosselló-Móra R. Shifting the genomic gold standard for the prokaryotic species definition. Proc Natl Acad Sci U S A. 2009;106(45): 19126-31.

76. Darling ACE, Mau B, Blattner FR, Perna NT. Mauve: multiple alignment of conserved genomic sequence with rearrangements. Genome Res. 2004; 14(7):1394-403.

\section{Publisher's Note}

Springer Nature remains neutral with regard to jurisdictional claims in published maps and institutional affiliations.

Ready to submit your research? Choose BMC and benefit from:

- fast, convenient online submission

- thorough peer review by experienced researchers in your field

- rapid publication on acceptance

- support for research data, including large and complex data types

- gold Open Access which fosters wider collaboration and increased citations

- maximum visibility for your research: over $100 \mathrm{M}$ website views per year

At BMC, research is always in progress.

Learn more biomedcentral.com/submissions 